\title{
Concepções acerca do laudo médico no processo de escolarização
}

\author{
Conceptions about the medical report in the schooling process
}

Concepciones sobre el informe médico en el proceso de escolarización

Gabriela Prado da Fontoura

Professora e psicóloga clínica, especialista em Atendimento Educacional Especializado, Sapiranga, RS, Brasil

E-mail: gabpradofont@gmail.com ORCID: https://orcid.org/0000-0002-6060-723X

Helena Venites Sardagna

Professora doutora da Universidade Estadual do Rio Grande do Sul, Osório, RS, Brasil

E-mail: helena-sardagna@uergs.edu.br ORCID: https://orcid.org/0000-0002-6175-9542

Recebido em 14 de janeiro de 2020

Aprovado em 09 de agosto de 2021

Publicado em 31 de agosto de 2021

\section{RESUMO}

O presente artigo se propõe a discutir as concepções de profissionais da educação da região do Vale do Rio dos Sinos, no estado do Rio Grande do Sul, sobre o laudo médico, assim como problematizar a exigência desse documento para o atendimento educacional especializado (AEE). Pensar sobre isso se traduz numa forma de colaborar para 0 entendimento das interações interdisciplinares da saúde e da educação, dos limites e das possibilidades de cada área, assim como dos discursos que contribuem, ou não, na reflexão sobre os processos pedagógicos. Para o estudo, foi realizada a coleta de dados por meio de um questionário semiestruturado aplicado aos profissionais da educação, utilizando-se o Google Forms. O exercício analítico originou três eixos de discussão: (1) Entre teorias e práticas: o laudo, o aluno público-alvo do AEE (PAEE) e o profissional de AEE; (2) O laudo médico como detentor do saber do PAEE; (3) Entre caminhos necessários: a construção conjunta. A discussão evidenciou que o discurso médico/clínico (o laudo) ainda é motivo de restrição ao atendimento educacional especializado e que os educadores percebem a superação dessa lógica considerando a interdisciplinaridade.

Palavras-chave: Atendimento educacional especializado; Laudo médico; Alunos com deficiência.

\section{ABSTRACT}

This article aims to discuss the conceptions of education professionals from the Rio dos Sinos Valley region in the state of Rio Grande do Sul about the medical report, as well as to discuss the use of this document for specialized educational assistance (AEE). Thinking about this translates into a form of collaboration for the understanding of interdisciplinary interactions of health and education, the limits and possibilities of each area, as discourses that contribute or not to the reflection on the pedagogical processes. For the study, data 
http://dx.doi.org/10.5902/1984686X41866

were collected through a semi-structured questionnaire applied to education professionals using Google Forms. The analytical exercise originated three axes of discussion: (1) Among theories and practices: the student, the AEE target audience (PAEE) and the AEE professional; (2) The medical report as holder of the knowledge of PAEE; (3) Among necessary paths: joint construction. The discussion evidenced by the medical / clinical discourse (or report) is still a reason for restricting the specialized educational assistance and that the educators perceived as logical overcoming considering an interdisciplinarity.

Keywords: Specialized Educational Assistance; Medical report; Students with disabilities.

\section{RESUMEN}

El presente artículo es un estudio sobre las concepciones de profesionales de la educación sobre la región de Rio Grande do Sul, sobre el tema de la enseñanza, así como los documentos para la atención educativa especializada. Pensar, si se traduce en una forma de colaboración para el entendimiento de las interacciones interdisciplinarias, los límites y posibilidades de cada área, así como los discursos pueden auxiliar o no, en la reflexión de los procesos de desarrollo pedagógico. El estudio fue realizado a partir de una recolección de datos a través de un cuestionario semiestructurado utilizando los datos de la educación, utilizando Google Forms y una revisión de artículos científicos en la base del SciELO Scientific Electronic Library Online. La lectura minuciosa y los temas representativos son originarios de tres ejes de enseñanza: Entre las teorías y prácticas: el laudo, el alumno PAEE y el profesional de AEE; El laudo como poseedor del saber del PAEE; y los caminos necesarios: una construcción conjunta. Una discusión evidenciada por el discurso médico / clínico, o sea, el laudo aún fue el motivo de una falla en la atención educativa y que los educadores perciben una superación considerando una interdisciplinariedad.

Palabras clave: Asistencia educativa especializada; Informe médico; Estudiantes con discapacidad.

\section{Introdução}

Há um espaço de saber que se mantém em funcionamento carregando, em sua história, vestígios da lógica de normalização dos modos de ser e de pensar em certos processos de escolarização. Há um espaço legitimado que possui, em suas entranhas, fragmentos de uma história higienista e excludente. A escola, ambiente de educação formal, foi adentrada pelas áreas da saúde que, por vezes, buscam justificar os comportamentos tidos como desviantes, colaborando para a padronização e a divisão entre normais e anormais. Por outro lado, buscam auxiliar na percepção da individualidade do aluno.

Nesse sentido, o laudo médico suscita opiniões divergentes e, por vezes, funciona como marcador do processo escolar de muitos dos sujeitos com deficiência. Nessa perspectiva, este artigo objetiva compreender as concepções dos profissionais da 
http://dx.doi.org/10.5902/1984686X41866

educação sobre o laudo e a exigência desse documento para a oferta do atendimento educacional especializado (AEE).

A temática se mostra necessária porque basta circular pelos corredores das escolas para perceber que o laudo médico é motivo de tensões dentro das instituições onde é requerido, apesar de não ser uma prerrogativa da legislação que prevê a inclusão. Pensar sobre essa questão é uma forma de colaborar para o entendimento das interações interdisciplinares entre as áreas da educação e da saúde, bem como dos limites e das possibilidades de cada área. Da mesma forma, é preciso compreender como os discursos que vão constituindo verdades sobre o laudo no contexto escolar podem auxiliar, ou não, para a reflexão sobre os processos pedagógicos. A problematização acerca do laudo no processo de escolarização foi evidenciada em estudos encontrados na busca por artigos científicos na base SciELO (Scientific Electronic Library Online), sob descritores "educação - laudo - deficiência" e "atendimento educacional especializado - laudo - deficiência", publicados a partir de 2015. Contudo, pela pequena quantidade de artigos disponíveis no referido repositório, foi agregado um estudo de 2011. No contingente encontrado, foram considerados quatro artigos que apresentaram uma proximidade com o tema aqui discutido, que retratavam o contexto educacional brasileiro (LIMA; MENDES, 2011; OLIVEIRA; MANZINI, 2016; PALMA; CARNEIRO, 2018; KRANZ; CAMPOS, 2020).

Lima e Mendes (2011, p. 1) realizaram um estudo que objetivou "analisar a coerência entre a finalidade legal da escolarização da pessoa com deficiência intelectual e os sentidos atribuídos pela família a essa escolarização na classe comum da escola regular". A pesquisa identificou que as expectativas de 24 familiares de alunos com algum tipo de laudo são: a aprendizagem, a socialização e o desenvolvimento, num sentido amplo. As autoras evidenciaram ainda que essas famílias não desejam a certificação de seus filhos por meio da "terminalidade específica"1, uma das medidas adotadas para alunos com laudo de deficiência intelectual, pois não há preocupação com a permanência e o sucesso deles na escola, além de responsabilizá-los pelo seu sucesso ou fracasso.

Oliveira e Manzini (2016) fizeram um estudo de caso no contexto de uma sala de recursos multifuncional de um município brasileiro e, a partir dele, pontuam sobre a exclusão de muitos alunos do atendimento educacional especializado, em sala de recursos multifuncional (SRM), por não serem considerado público-alvo da educação especial, apesar de não haver necessidade do laudo. Os autores problematizam os motivos pelos quais os alunos eram encaminhados para a SRM, sendo um deles o rendimento em relação 
http://dx.doi.org/10.5902/1984686X41866

ao processo de alfabetização e, em algumas situações, por deficiência intelectual ou pela própria solicitação dos pais. Concluem que a estrutura identificada diverge da legislação quanto aos alunos público-alvo da Educação Especial, pois uma parcela dos alunos matriculados na SRM é atendida por apresentarem dificuldade de aprendizagem e comportamento.

Kranz e Campos (2020, p. 1) propuseram um estudo que analisa "políticas públicas, práticas diagnósticas e pedagógicas na educação especial, destacando concepções e articulações entre elas, principalmente afetas ao trabalho de psicólogos e professores". Entre seus achados, a partir de um estudo de caso de criança com laudo de deficiência intelectual, identificaram forte acento da perspectiva clínica nas políticas e nas práticas, problematizando a presença da concepção individual e biológica da deficiência, que responsabiliza o indivíduo pelo insucesso. Evidenciam ainda que "as mediações pedagógicas são de baixa qualidade, infantilizadoras, de modo que mais resultam em exclusão e inferiorização do que na aprendizagem e no desenvolvimento do sujeito" (KRANZ; CAMPOS, 2020, p. 1).

O estudo de Palma e Carneiro (2018) também é pertinente para a discussão aqui proposta: as autoras enfatizam o olhar social em escolas do campo sobre a deficiência intelectual, a partir de um levantamento com 31 professores de três escolas. Elas evidenciam que não há exigência do laudo para a matrícula; no entanto, identificam que, em algumas situações, a deficiência intelectual é produzida socialmente, na medida em que não considera a heterogeneidade dos indivíduos em relação à aprendizagem, além de criar barreiras para o aluno por falta de estratégias pedagógicas do ambiente escolar.

Esses estudos, pela raridade da discussão, corroboram a importância de pesquisar concepções acerca do laudo médico no processo de escolarização, pois é visível que a função do laudo nem sempre contribui para a efetivação da inclusão. Dos quatro estudos, dois informam que, para receber atendimento, não há exigência do laudo médico (PALMA; CARNEIRO, 2018; OLIVEIRA; MANZINI, 2016), o que está em consonância com as diretrizes das políticas educacionais vigentes. Por outro lado, a partir do estudo de Oliveira e Manzini (2016), percebemos que não se exige laudo para atendimento; no entanto, há situações em que se encaminham para o AEE alunos que não fazem parte do público-alvo previsto na legislação.

Outro ponto que consideramos relevante, presente em dois artigos (PALMA; CARNEIRO, 2018; KRANZ; CAMPOS, 2020), é a problematização acerca de como é 
http://dx.doi.org/10.5902/1984686X41866

constituído o olhar para o sujeito que frequenta o atendimento educacional especializado na escola. Os significados muitas vezes produzem indivíduos a corrigir, depositando no próprio sujeito a responsabilidade pela não aprendizagem.

Para cumprir o objetivo proposto, foram coletados dados junto a profissionais da educação, por meio de um questionário semiestruturado, aplicado a 33 profissionais da educação da região do Vale do Rio dos Sinos $(\mathrm{RS})^{2}$ no Rio Grande do Sul. No formulário, que era respondido via Google Forms, as perguntas diziam respeito ao laudo médico para a instituição de ensino. Por fim, foi realizada a tabulação e organização dos dados em temas.

Os temas representativos foram organizados em eixos que serão objeto de discussão do presente artigo. Os três eixos são: (1) Entre teorias e práticas: o laudo, o aluno PAEE e o profissional de AEE; (2) O laudo médico como detentor do saber do PAEE; e (3) Entre caminhos necessários: a construção conjunta. $\mathrm{Na}$ primeira seção, aborda-se o conhecimento que os profissionais da educação têm sobre a prática do atendimento educacional especializado, assim como sobre a existência desses profissionais nas instituições de ensino. A seção ainda analisa como ocorre a prática do AEE e quais são os critérios para a inserção do aluno público-alvo do atendimento educacional especializado (PAEE). A segunda seção problematiza a necessidade do laudo médico para considerar o estudante da escola como um aluno com deficiência, diante das concepções dos professores, e como os profissionais da educação que responderam à pesquisa concebem o laudo de diagnóstico clínico na prática educacional. Por fim, a terceira seção ressalta os aspectos relacionados às concepções que os educadores possuem da necessidade ou não dos saberes da área da saúde para o desenvolvimento da prática pedagógica.

\section{O laudo médico enquanto dispositivo de norma e anormalidade}

Pensar na não linearidade da educação especial se faz necessário para a compreensão dos processos de escolarização e inclusão, pois, em cada época, em cada momento histórico, houve uma finalidade educativa diante das políticas voltadas às pessoas com deficiência. Conhecer esse caminho histórico auxilia no entendimento das influências do passado no ensino presente e retrata a escola como um espaço de adversidades práticas e funcionais, onde atualmente o aluno com deficiência está incluído.

De certo modo, a concepção acerca da pessoa com deficiência vai sendo modificada na história. Entretanto, nos dias atuais, a população continua sendo pautada por 
http://dx.doi.org/10.5902/1984686X41866

parâmetros a partir dos quais todos os sujeitos são comparados. Os sistemas educacionais fazem uso desses parâmetros em seus próprios currículos escolares, desdobrados em seus serviços de apoio, que existem para tornar o sujeito aluno o mais próximo daquilo que é considerado ideal na escolarização. Para compreender esses deslocamentos, é pertinente trazer alguns fragmentos históricos que ilustram a emergência dos discursos vigentes na atualidade.

Para Canguilhem (2002), a anormalidade é uma condição inventada em meio aos processos biopolíticos sobre a população, que ocorreram por volta dos séculos XVII e XVIII, a partir de um conjunto de atributos encontrados na maior parte dos indivíduos de uma espécie determinada. O autor destaca também que anomalia significa desigualdade, aspereza. Assim, passa-se a compreender por "normativo qualquer julgamento que aprecie ou qualifique um fato em relação a uma norma" (CANGUILHEM, 2002, p. 96). Nesse sentido, a anormalidade, assim como a normalidade, é invenção da Modernidade.

Conforme Bianchetti (1995), nesse contexto, a deficiência passou a ser compreendida como uma disfunção do processo de produção, e a visão teológica da pessoa com deficiência perdeu força, dando espaço para ideias organicistas. Com isso, a ciência médica passou a atuar como aparato normalizador, criando critérios na forma de binômios como apto/não apto, normal/anormal (COLOMBANI; MARTINS, 2017).

Para França (2014, p. 6), a crescente racionalização, a partir do século XVIII, estabeleceu a medicina como "campo de conhecimento privilegiado e de mais impacto na vida das pessoas com deficiência". Assim, na mudança do século XVIII para o século XIX, para Foucault (1987), não é mais sobre o corpo que se exerce o poder, é sobre a alma, sobre a subjetividade. Sobre o corpo, deve suceder a correção (FOUCAULT, 1987). "Essas grandes regulações globais que proliferam ao longo do século XIX, nós as encontramos, é claro, no nível estatal, mas também abaixo do nível estatal, com toda uma série de instituições subestatais, como as instituições médicas, as caixas de auxílio, os seguros, etc." (FOUCAULT, 1999, p. 299).

Nesse contexto, cresce um movimento higienista, que se tornou expressivo no Brasil em meados do século XX e uma lógica de identificar aptos e não aptos. Cabe ressaltar que, também no século XX, de acordo com França (2014), a medicina estava sob o princípio científico da classificação. Nesse cenário, em 1976, a Organização Mundial da Saúde elaborou o documento "Classificação Internacional de Deficiências, Incapacidades e Desvantagens" (CIDID). Assim, o movimento higienista consolidou-se como uma ação que 
http://dx.doi.org/10.5902/1984686X41866

uniu saúde e educação com a finalidade de alcançar os escolares e suas famílias (COLOMBANI; MARTINS, 2017).

Para estabelecer os sujeitos como aptos e não aptos, é recorrente a presença do laudo médico, solicitado por profissionais da educação, a fim de identificar aqueles que escapem à norma constituída socialmente. Assim, para Sathler (2008), os diagnósticos nos laudos são dispositivos de individualização e funcionam como poderosos instrumentos de exclusão e normalização, visto que agem na condução da população às medidas centrais, estabelecidas pela média, que pauta a norma.

O saber médico, ao passar a nomear um desvio, parece fornecer diagnósticos sobre a possibilidade ou não de aprender, ou seja, suas potencialidades e dificuldades. A presença de um documento que descreva a anormalidade do sujeito talvez tenha se constituído como uma das estratégias para se escolarizar os alunos que adentram os muros da escola sob a lógica da inclusão (RAMOS, 2014). O sujeito considerado anormal foi nomeado de diferentes modos ao longo dos tempos: débil, retardado, criança problema, fracasso escolar. A ideia era identificá-los e discriminá-los como "diferentes" (ROSÁRIABARBOSA; SOUZA, 2012, p. 169).

A lógica de norma e anormalidade operada pela sociedade e pela escola foi marcada, em cada época, por construções sociais que permeiam o imaginário até hoje. Para GalliFonseca (2012, p. 24), o homem tornou-se "doente de uma história" e, ao buscar transformá-la e se transformar, acabou por acolher o erro. Tornou-se culpado por aquilo que pensa que não pode modificar: sua herança social. Assim, as mudanças na lógica de inclusão da pessoa com deficiência, no interior das escolas e com as atuais políticas de inclusão, podem ser consideradas tentativas de mudar a futura herança social.

Contudo, os processos de normalização foram se atualizando em convergência com as práticas sociais de cada contexto. Não significa que as práticas atuais de inclusão deixaram de hierarquizar, classificar e posicionar os sujeitos público-alvo da educação especial em torno da norma. Nos deslocamentos evidenciados nas próprias políticas educacionais, é nítida a oferta de serviços de apoio (como é o AEE), que, por mais que dizem acolher as diferenças, pautam suas práticas em médias. Por outro lado, há que se considerar os avanços significativos na garantia dos direitos dos sujeitos.

Na Política Nacional de Educação Especial na Perspectiva da Educação Inclusiva, o AEE possui função complementar ou suplementar à formação do aluno por meio de recursos que eliminem as barreiras para sua participação na sociedade e no 
http://dx.doi.org/10.5902/1984686X41866

desenvolvimento da aprendizagem (BRASIL, 2008, 2009). A Resolução n. 4, Art. 1ํㅜㄹ orienta que o AEE deve ocorrer no turno inverso ao da aula, "nas salas de recursos multifuncionais ou em centros de Atendimento Educacional Especializado da rede pública, ou de Instituições comunitárias, confessionais ou filantrópicas sem fins lucrativos" (BRASIL, 2009). Porém, não versa sobre o laudo médico.

Em relação ao laudo, a Nota Técnica no 04, de 23 de janeiro de 2014 (BRASIL, 2014), frisa que o AEE é um atendimento de caráter pedagógico, e não clínico, não sendo considerado imprescindível o diagnóstico clínico - ou seja, o laudo. A Nota Técnica indica que deve ser elaborado o Plano de AEE, considerado o documento responsável por comprovar e assegurar o atendimento. Nesse sentido, minimiza o caráter medicalizante da educação.

Para Angelucci (2014, p. 124), é possível perceber a lógica "medicalizante e patologizante" na medida em que se adotam termos do campo biomédico para definir o público-alvo de atendimento do AEE. Um exemplo refere-se às pessoas com diagnóstico de transtornos globais do desenvolvimento (TGD). A autora questiona: quais seriam as condições teórico-práticas que os educadores possuem para chegar a uma conclusão sobre se um estudante apresenta TGD, se essa classificação é construída pelas nomenclaturas biomédicas? (ANGELUCCI, 2014). A nota técnica referida acima (BRASIL, 2014) orienta que os profissionais de ambas as áreas - educação e saúde - possam se articular para construir estratégias de ensino e aprendizagem que valorizem as potencialidades dos alunos PAEE.

Nesse sentido, faz-se necessário um olhar que problematize a exigência do laudo pelas escolas, pois a legislação não determina a sua existência como necessária ao AEE. Por outro lado, as instituições concebem o documento como obrigatório, automaticamente restringindo o direito universal de acesso à educação.

\section{Caminhos metodológicos}

O estudo se caracteriza por uma abordagem quali-quantitativa, definida por Minayo (1994) como a pesquisa capaz de conduzir o investigador à escolha de um problema particular, sendo o objeto analisado em toda sua complexidade. Assim, o estudo qualitativo busca compreender o contexto e contribuir para o processo de mudança frente ao estudado (DALFOVO; LANA; SILVEIRA, 2008). Já a abordagem quantitativa caracteriza-se pelo emprego da quantificação, tanto nas modalidades de coleta de informações quanto no 
http://dx.doi.org/10.5902/1984686X41866

tratamento destas com técnicas estatísticas (RICHARDSON, 1999), procurando traduzir em números os conhecimentos gerados pelo pesquisador.

Considerando o objetivo do estudo de discutir e compreender as concepções de profissionais da educação acerca do laudo, assim como problematizar a exigência desse documento para o AEE, realizou-se a coleta com 33 educadores das regiões informadas acima. Os educadores que colaboraram com o presente estudo pertencem a três redes de ensino (municipal, estadual e particular) e trabalham em sete municípios distintos: Sapiranga (12), Parobé (11), Novo Hamburgo (4), Campo Bom (2), Araricá (2), Nova Hartz (1) e Dois Irmãos (1). Dos profissionais que responderam à pesquisa, 11 são professores que ocupam a função de profissional do atendimento educacional especializado, 8 são profissionais na função de gestores, 5 são professores de áreas do conhecimento dos anos finais do ensino fundamental, 5 são professores de pedagogia dos anos iniciais, 1 é educadora fora do contexto educacional e 4 são professores que não especificaram suas funções.

Os educadores que contribuíram com este estudo autorizaram a publicação das suas respostas mediante consentimento livre e esclarecido, preservando o anonimato. O questionário é composto por perguntas abertas e fechadas que são respondidas via Google Forms, um aplicativo que faz parte do Google Drive. O formulário construído é disponibilizado por um endereço eletrônico e, quando preenchido pelos respondentes, as respostas aparecem imediatamente na página do Google Forms do usuário que o criou (MATHIAS; SAKAI, 2013).

\section{Entre teorias e práticas: o laudo, o aluno PAEE e o profissional de AEE}

A luta pelo direito à educação para estudantes com deficiência tem propiciado um aumento significativo de matrículas desses alunos nas escolas de ensino regular (VIEIRA; RAMOS, 2018). Logo, "a escola precisa conceber a inclusão no seu Projeto Político Pedagógico (PPP) e colocar em funcionamento as medidas necessárias para promover a igualdade de condições para uma Educação Inclusiva" (PALMA; CARNEIRO, 2018, p. 162).

De acordo com Vieira e Ramos (2018), o aumento de estudantes com deficiência tem movido a criação de políticas educacionais para aperfeiçoar a proposta de oportunidades para todos. Sobre essa perspectiva, a Resolução CNE/CEB nำ 4, de 02 de outubro de 2009, ressalta, em seu Art. 1ํㅜ, a necessidade de implantação do Decreto no 7.611 , de 17 de novembro de 2011. Esse Decreto dispõe sobre os alunos PAEE nas classes comuns do 
ensino regular e no AEE. Dessa forma, as instituições devem inscrever os alunos com deficiência também na sala de recursos multifuncionais (SRM).

Partindo da necessidade de conhecer aquilo que existe entre a teoria e a prática do cotidiano educacional, buscou-se inicialmente verificar quais profissionais identificam e conhecem o AEE, assim como qual o critério para a inclusão de alunos nessa modalidade de atendimento e qual a importância desse serviço para a instituição de ensino. Em relação ao conhecimento desse serviço na instituição de ensino e qual o seu papel, apenas um dos entrevistados desconhece o que seria o AEE (Gráfico 1).

Gráfico 1 - Profissionais que conhecem o serviço de AEE

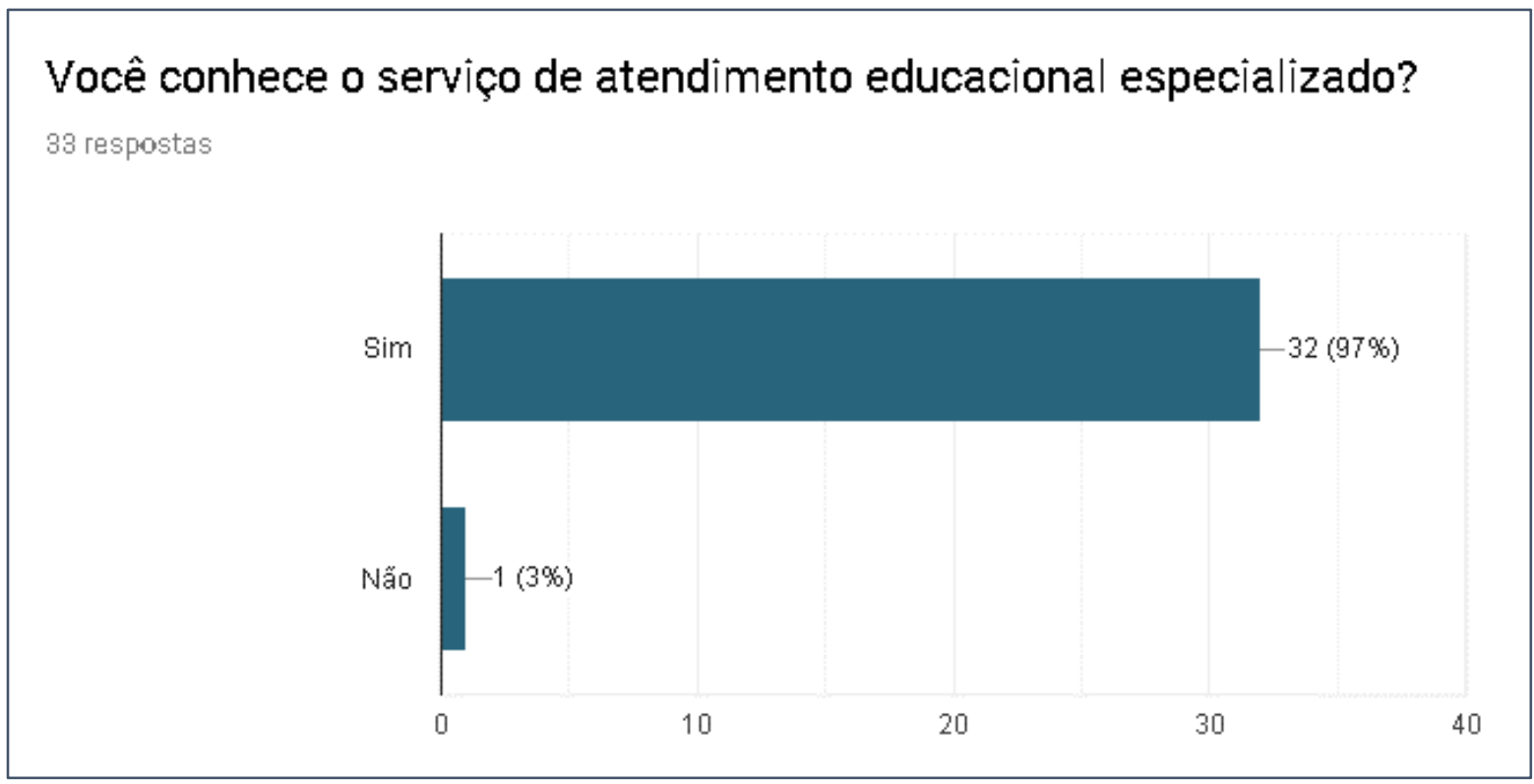

Fonte: Elaborado pelas autoras (2019).

Em relação à oferta do AEE, 90,9\% dos profissionais entrevistados identificam a presença do serviço na sua instituição, conforme apresenta o Gráfico 2. Como dispõe a Resolução no 04/2009, que institui as diretrizes operacionais para o AEE, o Projeto Político Pedagógico da escola deve institucionalizar a oferta do AEE. Percebe-se, portanto, que as instituições estão se adaptando às políticas de inclusão vigentes, pois, apesar de ser um serviço assegurado por lei, evidencia-se que quase $10 \%$ das escolas nas quais atuam os entrevistados não contam com esse atendimento. Esses dados permitem afirmar que 0 AEE ainda está em fase de consolidação. 
http://dx.doi.org/10.5902/1984686X41866

Gráfico 2 - Oferta de AEE na instituição de atuação dos profissionais

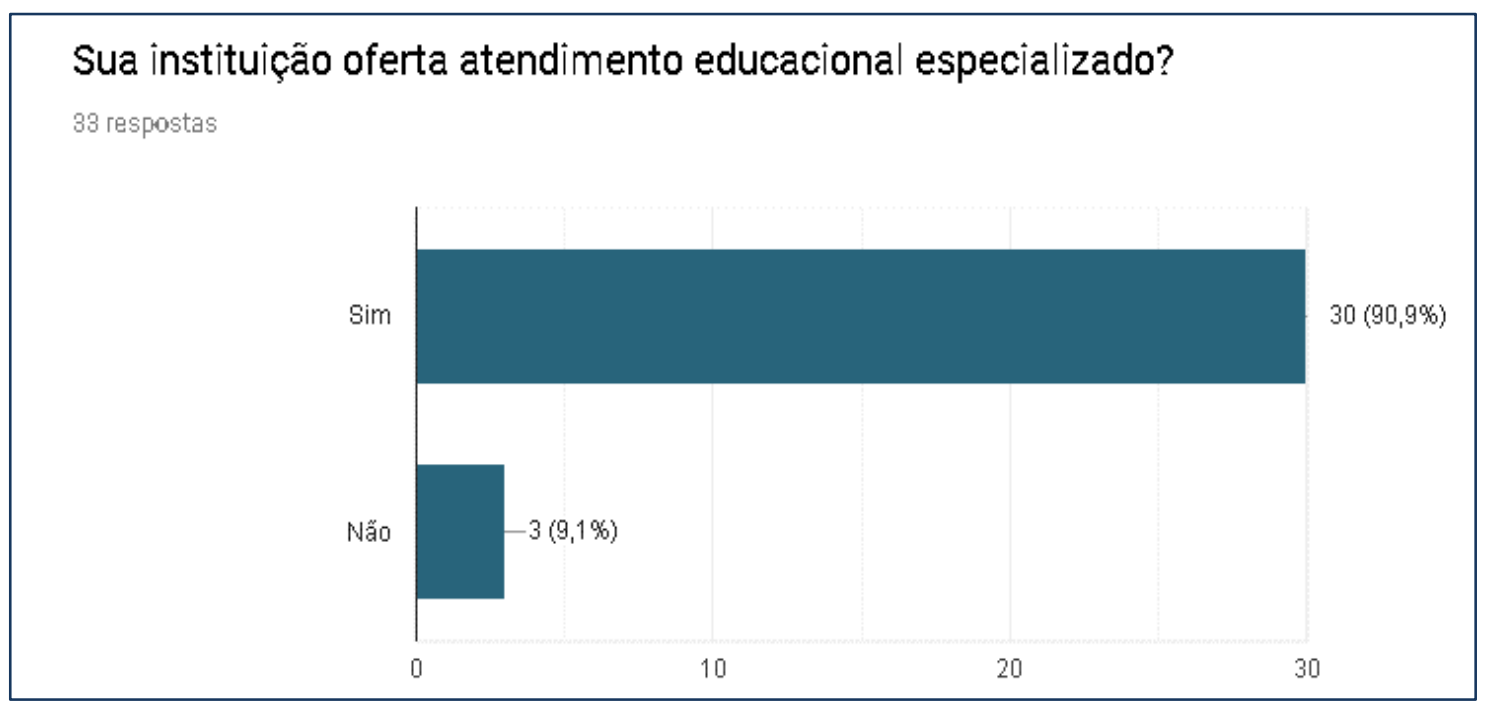

Fonte: Elaborado pelas autoras (2019).

Na sequência, os educadores que apontaram a existência do AEE na sua instituição responderam sobre a forma como é ofertada a modalidade de atendimento, bem como o critério para incluir o aluno no AEE. O trecho, a seguir, apresenta a resposta ${ }^{3}$ de um profissional diante do questionamento:

\begin{abstract}
O AEE é oferecido aos alunos público-alvo, sendo estes alunos com deficiência ou altas habilidades e superdotação, não sendo obrigatória apresentação de laudo médico. $O$ aluno poderá ser atendido mediante avaliação do professor do $A E E$, pois o $A E E$ é pedagógico e, quando se constata que o aluno possui uma deficiência, é elaborado o plano de $A E E$, onde são pensadas as intervenções adequadas, levando em consideração suas necessidades e potencialidades, buscando parcerias com atendimentos clínicos para atender às especificidades de cada aluno. Quando o professor do AEE sentir necessidade para que se comprove ou não se o aluno apresenta uma deficiência, pode-se buscar ajuda com uma avaliação clínica com neurologista, psicólogo, psicopedagogo, fonoaudiólogo entre outros, para então nortear o trabalho desenvolvido e realmente ter claro se o aluno é demanda ou não do AEE (RESPOSTA QUESTIONÁRIO, 2019).
\end{abstract}

Como já mencionado, os alunos são atendidos no contraturno escolar e, como mostra o depoimento a seguir, no mesmo turno da escolarização em alguns casos específicos. Na sala de recursos multifuncionais, os alunos são atendidos com periodicidade semanal, sendo o atendimento destinado ao aluno PAEE. Para o ingresso nessa modalidade de atendimento, conforme menciona o profissional no relato anterior, não há necessidade de laudo médico, uma vez que, para o trabalho pedagógico, pode ser feita a avaliação pelo professor de AEE, articulado com o professor da sala de aula comum e com a família. A Resolução 04/2009, no Art. 5ํ, refere que o AEE deve ocorrer prioritariamente na sala de recursos multifuncionais da própria escola ou em outro espaço de referência, no turno 
http://dx.doi.org/10.5902/1984686X41866

inverso. Nesse sentido, frente aos dados, evidencia-se que a concretização do AEE nem sempre atende à prerrogativa legal.

Outro profissional relata também sobre o parecer técnico que fornece subsídios para 0 atendimento dos alunos:

Realiza-se atendimento individual ou em grupo com duração de 50 minutos por semana. No mesmo turno de aula ou oposto, de acordo com o transporte. Quem é atendido são na maioria alunos com deficiência intelectual, transtornos globais e altas habilidades. Não tenho esse último público. $O$ critério é estudo de caso a partir de parâmetros pedagógicos para identificar algo que a nota técnica 2014 traz da área clínica. A meu ver, há uma contradição nesse documento. O professor de AEE deve identificar o aluno com possível deficiência intelectual, por exemplo, mas com critérios pedagógicos. O que costumo usar são instrumentos qualitativos para averiguar o contexto do aluno segundo Vygotsky, para antes de qualquer coisa, ver se é uma questão metodológica com o professor, ou algo do aluno. (RESPOSTA QUESTIONÁRIO, 2019)

Não existe um protocolo de identificação do sujeito PAEE. Entretanto, o profissional de AEE apresenta autonomia na organização do seu planejamento, conforme os relatos. A Nota Técnica nº 04/2014 apresenta as orientações sobre os documentos comprobatórios para os alunos PAEE e frisa que não se pode considerar imprescindível a apresentação do laudo médico, contudo, deixa a cargo do professor a articulação com o profissional da saúde, o que pode gerar diferentes compreensões e práticas nos contextos escolares. Sugere-se que, na primeira etapa do estudo de caso para a construção do Plano de AEE, possam ocorrer articulações entre os profissionais da área da saúde.

Contrariando essa orientação da Nota Técnica $n$ ำ4/2014, os relatos a seguir ressaltam que, para a inserção do aluno no AEE, é exigida a apresentação do laudo médico:

Temos uma profissional que atende na sala de AEE onde são atendidos alunos com laudo médico. O critério é que o aluno deve ter laudo médico. (RESPOSTA QUESTIONÁRIO, 2019)

O atendimento é feito para alunos que possuem laudo médico e que indicam alguma dificuldade relacionada à aprendizagem, ou alguma deficiência que requer atenção especial para a aprendizagem. (RESPOSTA QUESTIONÁRIO, 2019)

Nesse sentido, a perspectiva clínica é reforçada pela educação e sustentada pelo olhar da saúde. Para Angelucci (2014, p. 118), a educação utiliza-se de "diagnósticos em saúde" para organizar sua oferta de atendimento, fazendo permanecer a divisão entre sujeitos escolarizáveis e não escolarizáveis. Mesmo com a possibilidade de emitir um parecer pedagógico garantindo a inserção do aluno no atendimento, a preocupação com o 
http://dx.doi.org/10.5902/1984686X41866

laudo médico existe e, por vezes, parece atrelada ao status que os discursos da saúde exercem nas instituições de ensino.

A escola oferece atendimento individual para estes alunos com a professora do AEE uma ou duas vezes por semana, dependendo da disponibilidade. Inicialmente estes alunos tinham que ter laudo médico para frequentar o atendimento, mas agora não precisa. Contudo do meu ponto de vista ainda percebo que se o aluno tem laudo, representa ter preferência e mais permanência no atendimento e para ter monitoria na sala do que aquele que não tem. (RESPOSTA QUESTIONÁRIO, 2019)

Esses critérios de atendimento podem estar atrelados às mudanças nas políticas de inclusão. Sobretudo, vale lembrar que a Nota Técnica no 04/2014 reconhece que a existência de um laudo médico não é condicionante para a inserção do aluno, pois o AEE se caracteriza por atendimento pedagógico, e não clínico. Mesmo assim, evidencia-se que alguns profissionais seguem operando na lógica do laudo como garantia de acesso, esquecendo que exigi-lo é restringir o direito ao acesso à educação.

Atualmente o parecer pedagógico do professor de AEE ganha relevância e, de acordo com Santiago, Santos e Melo (2017), passa a sustentar o processo decisório sobre o ingresso do aluno no serviço, bem como sua inserção como aluno PAEE no Censo Escolar MEC/INEP. Para Pasian, Mendes e Cia (2017, p. 14), é preciso que "os decretos que dispõem sobre o AEE sejam repensados", visando à fiscalização, a fim de que seja garantido o direito à educação e à permanência do aluno PAEE.

Dos profissionais entrevistados, quase a totalidade manifestou conhecer 0 atendimento educacional especializado, conforme apresentado no Gráfico 1. Os profissionais responderam sobre a forma como percebem o AEE, versando a respeito das diferentes definições da necessidade desse serviço para a escola. É apresentada nas respostas a essencialidade do profissional do AEE. Os fragmentos a seguir apresentam essas esferas:

O serviço é um apoio pedagógico para o aluno, para o professor e escola em geral, quando se trata de educação especial e inclusão como um todo. Esse profissional articula-se com diferentes áreas e serviços de apoio para auxiliar no acesso arquitetônico e de conhecimento acadêmico da vida cotidiana. (RESPOSTA QUESTIONÁRIO, 2019)

O AEE é um serviço essencial para a consolidação da proposta de educação inclusiva, que consiste em um trabalho em equipe para planejar e possibilitar estratégias pedagógicas e recursos de acessibilidade que promovam a educação de qualidade a estudantes que sejam pessoas com deficiência, transtorno global de desenvolvimento ou altas habilidades/superdotação, de acordo com suas características e necessidades. (RESPOSTA QUESTIONÁRIO, 2019) 
http://dx.doi.org/10.5902/1984686X41866

Superar as barreiras relativas à homogeneização do sistema de ensino, que, ao mesmo tempo, defende práticas educacionais e impossibilita a consideração dos tempos individuais (SANTIAGO; SANTOS, 2015), não é uma atribuição exclusiva do professor do AEE. Essa tarefa envolve diferentes protagonistas do contexto institucional, ao desenvolverem práticas que vão regendo o cotidiano escolar. Entretanto, o que se vê hoje são práticas em que o AEE se torna responsável pela demanda de inclusão da escola, como se o aluno incluído não fosse pertencente à classe comum, mas sim ao profissional de AEE.

Sob essa perspectiva, concordamos com Angelucci (2014), que, ao referir-se ao público-alvo da educação especial, problematiza a lógica médica e a procura, nos sujeitos, daquilo que os distancia de uma suposta normalidade. A partilha constituída nos espaços escolares, entre os que frequentam somente a sala de aula comum e os que frequentam também o serviço de $A E E$, aproxima-se das lógicas que delimitam a partilha entre normal e anormal. Há que reconhecer que o AEE pode ser um dos responsáveis pela dimensão pedagógica do aluno PAEE, e também pelas orientações aos professores, mas não é o único. Todos os professores, independentemente da sua função, são os responsáveis pela disseminação de conhecimentos que colaborem com o acesso à educação de todos.

$O$ professor do AEE tem a atribuição de identificar, elaborar e organizar recursos pedagógicos e de acessibilidade (BRASIL, 2009). Para Santiago, Santos e Melo (2017, p. 634), o profissional de AEE visa a colaborar no processo de inclusão em educação, ou seja, na "eliminação de barreiras para a plena participação e aprendizagem dos alunos, considerando suas necessidades específicas". Além disso, os professores veem nesses profissionais uma possibilidade de se certificarem do que está sendo feito junto ao aluno em sala de aula, depositando neles a expectativa de amparo em relação à sua prática (BAPTISTA; VIEGAS 2016).

A legislação sinaliza que se pode considerar como professor capacitado para as práticas inclusivas todo aquele profissional que tem certificação para o desempenho da docência, ou seja, com conhecimentos didáticos para planejar, traçar objetivos, mediar situações de aprendizagem, organizar a ação pedagógica e avaliar os estudantes. No entanto, para Vieira e Ramos (2018), muitos profissionais trazem trajetórias de aprendizagem marcadas pelas diferenças significativas, não se vendo capacitados para executar essas funções. 
http://dx.doi.org/10.5902/1984686X41866

Diante das respostas descritas, são manifestadas posições sobre a necessidade do AEE. Entretanto, é pertinente problematizar a compreensão desse atendimento pelo sujeito entrevistado no contexto institucional, uma vez que há uma grande expectativa nesse serviço, o que faz parecer que o trabalho de sala de aula é secundário. Os fragmentos a seguir traduzem a concepção de três profissionais da educação sobre esse serviço:

\begin{abstract}
O AEE é uma ferramenta importante na escola inclusiva, mas não é utilizado de forma correta. É preciso mudanças estruturais na educação, para que tanto o AEE, quanto a inclusão sejam efetivas para alunos com deficiência e tantos outros que não se encontram na ordem normal do sistema. (RESPOSTA QUESTIONÁRIO, 2019)
\end{abstract}

De grande importância, mas demora muito até que o aluno tenha o laudo para ser atendido pelo profissional, o que atrasa muito mais a criança. (RESPOSTA QUESTIONÁRIO, 2019)

Serviço essencial para atendermos nossa atual demanda constituído por
alunos que trazem as mais diferentes necessidades educativas especiais.
Somente os serviços oferecidos pela área da saúde não atendem mais a
demanda, as salas de AEE vêm fortalecer esse atendimento sendo um
atendimento rápido pela proximidade com aluno. (RESPOSTA
QUESTIONÁRIO, 2019)

Os trechos estabelecem diferentes concepções acerca do serviço prestado, assim como os possíveis déficits que podem se originar da exigência do laudo médico. Aparece no último fragmento, também, a ideia de que os profissionais da saúde não atendem mais a demanda, fazendo compreender que o AEE vem cumprir a funcionalidade da saúde na escola, como se o atendimento da SRM fosse caracterizado por ser clínico - e propusesse uma cura, inclusive, para o que não é doença - ou, ainda, que em algum momento na história da educação a saúde tivesse suprido tal demanda.

Essa linha tênue de compreensão da prática do AEE, assim como da educação inclusiva, apresenta os paradigmas educacionais fundamentados no direito da criança, sendo que é reforçado na Nota Técnica no 04/2014 (BRASIL, 2014) o fortalecimento da relação pedagógica no contexto escolar, em detrimento de um modelo pautado em um diagnóstico clínico. Para Angelucci (2014, p. 125), é preciso que o educador tenha o "compromisso ético-político de criar um projeto que pense a partir das categorias das ciências da educação", para assim haver diferentes formas de apropriação de conhecimentos e para não manter a indústria de diagnósticos no campo educacional. 


\section{O laudo como detentor do saber do PAEE}

Para Sathler (2008), os laudos são instrumentos poderosos de exclusão. Nomeia-se um desvio do padrão, detém-se o "saber" sobre o aprender do outro e exclui-se o que Angelucci (2014) nomeia de "as diferenças funcionais". Olha-se para o "faltante", para aquilo que "destoa" e foge da norma. De acordo com Angelucci (2014), criamos a "abstração da pessoa deficiente", nomeando-a como aquela para quem falta algo. Depois de identificadas as diferenciações existentes entre os sujeitos, aquele que é percebido diante da norma como faltante precisaria do laudo. Com que propósito?

Diante da divergência sobre a exigência ou não do laudo para inserir o aluno PAEE no $A E E$, torna-se importante compreender quais são os caminhos traçados e o entendimento dos profissionais a respeito das políticas de inclusão. Para Santiago e Santos (2015), o professor de AEE pode se tornar o grande desencadeador de questões e articulações do desenvolvimento de políticas e práticas de inclusão e exclusão na escola. O Gráfico 3 representa as respostas sobre as concepções da necessidade do laudo para considerar o aluno como tendo deficiência.

Gráfico 3 - O uso do laudo diagnóstico para considerar o aluno como tendo deficiência

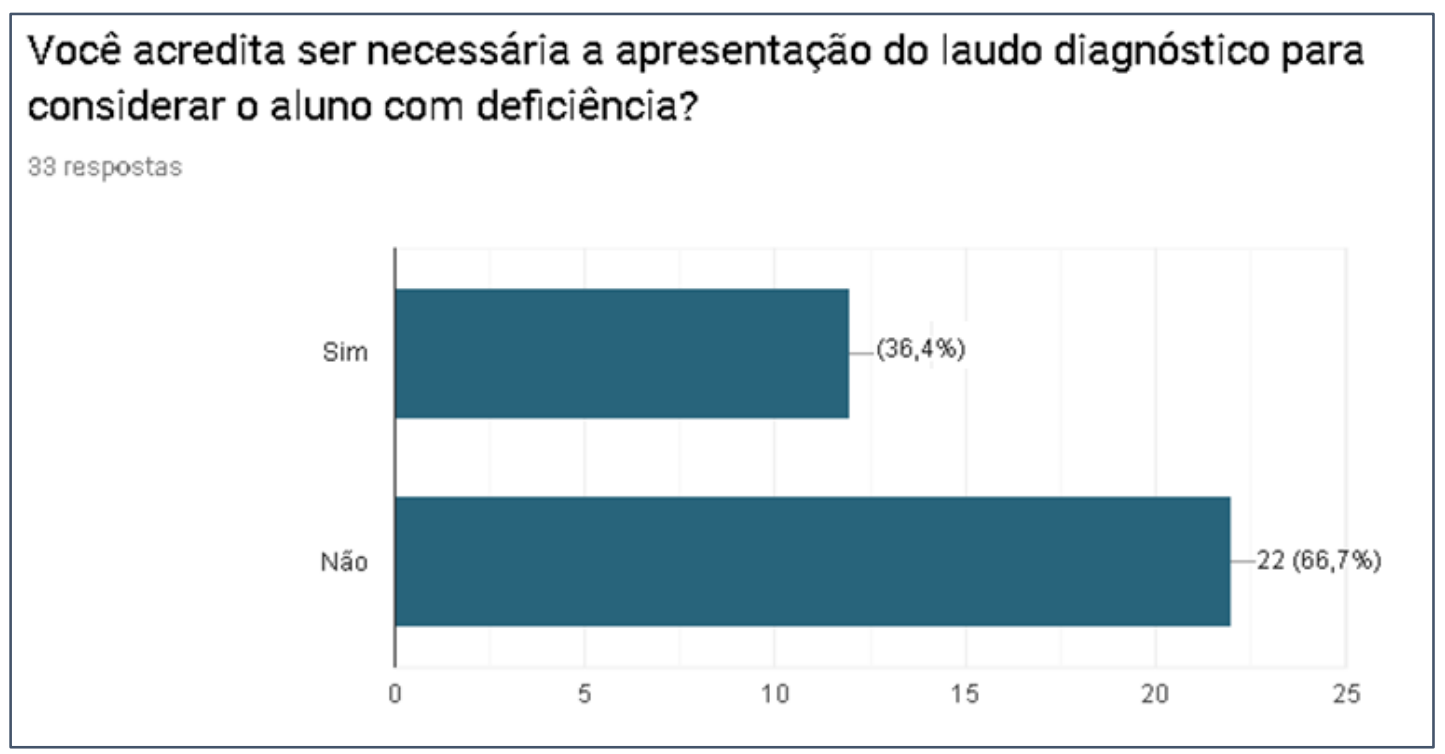

Fonte: Elaborado pelas autoras (2019).

Dos educadores que responderam à pesquisa, 36,4\% avaliam ser necessária a apresentação do laudo para considerar o aluno com deficiência. Entretanto, em suas justificativas, percebe-se o uso do laudo como um documento de apoio, e não exclusivo detentor do diagnóstico. Os profissionais que responderam que não é necessário o uso do 
http://dx.doi.org/10.5902/1984686X41866

laudo para considerar um aluno com deficiência apresentam a possibilidade da Nota Técnica $\mathrm{n}^{\circ} 04$ como suporte necessário e suficiente para inserir o aluno no atendimento.

Nas questões pedagógicas os professores têm total autonomia para definir as necessidades dos alunos. Mas o laudo contribui para esclarecer e direcionar alguns pontos também, mas não exclusivamente com necessidade de ser apresentado. (RESPOSTA QUESTIONÁRIO, 2019)

O laudo é uma confirmação, não deve limitar as intervenções precoces, ou minimizar a capacidade do aluno. (RESPOSTA QUESTIONÁRIO, 2019)

Entende-se que essa postura de exigir um laudo para considerar o aluno como deficiente não busca por respostas imediatas no campo da saúde, mas manifesta-se como complementar à prática pedagógica. O objetivo do documento não seria impor diagnósticos, mas sim isentar os indivíduos da ação educativa.

Para Angelucci (2014), é nas contradições que enriquecemos nossas culturas. Dessa forma, alguns educadores apresentaram respostas divergentes das evidenciadas até então:

Acho negligência um professor AEE dar diagnóstico para o aluno (nota técnica), pois o mesmo não foi capacitado. Muita responsabilidade. (RESPOSTA QUESTIONÁRIO, 2019)

O laudo diagnóstico é um documento que nos dá um respaldo médico em relação a sua saúde. Penso ser necessário termos o diagnóstico para nível de informação e amparo legal porque, apesar de termos professores especialistas atuando no AEE, é bastante complicado atestar, por exemplo, uma deficiência intelectual sem nenhum exame mais qualificado. A legislação diz que podemos aplicar a Nota Técnica, mas nem todos estão capacitados e seguros para realizar este procedimento. (RESPOSTA QUESTIONÁRIO, 2019)

Esses trechos mostram o desconhecimento da prática do AEE, pois, como descrito nas respostas, concebem o professor desse serviço como alguém que pode "dar diagnósticos" - o que não está previsto em nenhum regulamento do AEE. A inclusão é um processo que precisa ser pensado de forma coletiva e contextualizado no cotidiano escolar. Da mesma forma, é preciso reconhecer que profissionais da saúde não devem responder como detentores dos conhecimentos pedagógicos.

Para Santiago, Santos e Melo (2017, p. 640), a proposta de inclusão implica assumir "novas lógicas no plano individual, coletivo e institucional" no que tange às diversas dimensões. Não à toa, há educadores(as) que se dizem incapazes de trabalhar com essa população especial (ANGELUCCI, 2014). Ainda para a autora, existem profissionais com estudo e conhecimento, mas que acreditam que sua formação tem sido dispensada, em nome de uma formação paramédica. 
http://dx.doi.org/10.5902/1984686X41866

Novamente, nos fragmentos apresentados, percebem-se os discursos em torno do laudo. Mais uma vez, a burocracia na busca por um documento que diga o que falta no aluno (ou a taxonomia na qual ele se encontra) se faz presente no discurso do educador.

\section{Laudo é um processo demorado, demoram para conseguir vaga para atendimento, estes são curtos e em tempo espaçado, o que torna ainda mais lento um diagnóstico. $O$ aluno não pode esperar para que seja feito um trabalho específico com ele em função de sua necessidade. (RESPOSTA QUESTIONÁRIO, 2019)}

Nesse sentido, Baptista e Viegas (2016) problematizam a necessidade de auxílio para a identificação de casos e a realização de diagnósticos dentro da própria instituição escolar. Dessa forma, isso se justifica em função da burocracia e da demora no retorno dos resultados por parte dos centros diagnósticos. Para Angelucci (2014, p. 124), legitima-se a lógica médica "pelo discurso da desnecessidade dos saberes educacionais", os quais devem ser substituídos por processos de triagem, intervenção breve e encaminhamento para serviços de saúde.

Diante dessa lógica identificada em relação ao laudo para considerar um indivíduo como aluno com deficiência, o documento surge como informação de apoio ao conhecimento da prática pedagógica e do AEE. Da mesma forma, o parecer se coloca como recurso para suprir a lentidão da burocracia dos serviços de apoio à educação. Algumas respostas abordam ainda a multidisciplinaridade no processo de considerações sobre a pessoa com deficiência:

Acho que o aluno deve ter o laudo sim, mas que este deveria ser feito por toda a equipe que vem acompanhando, como psicólogo, fonoaudiólogo, professor da turma, e não só o médico que vê este indivíduo algumas vezes nas consultas e em exames. (RESPOSTA QUESTIONÁRIO, 2019)

Acredito que é necessária uma avaliação multidisciplinar para que se feche um diagnóstico de deficiência, para que realmente o aluno possa ser atendido de acordo com as suas dificuldades e possibilidades. (RESPOSTA QUESTIONÁRIO, 2019)

Cabe ressaltar e refletir sobre como o laudo diagnóstico colabora com a prática pedagógica. Não obstante, essas instâncias pouco ou nada conversam entre si, ocorrendo apenas o encaminhamento de alunos para a saúde, sendo diagnosticados, rotulados e devolvidos para a escola. O laudo clínico se apresenta como principal elemento orientador das práticas dos serviços de apoio e se constitui instrumento mediador das práticas escolares. Assim, não ocorre a elaboração de planejamentos que proponham ações intersetoriais. O mesmo muitas vezes pode ocorrer com a escola e o AEE: encaminha-se o 
http://dx.doi.org/10.5902/1984686X41866

aluno com suposta dificuldade para o atendimento especializado e espera-se que esse serviço contribua para que o aluno se enquadre na norma.

O laudo não é - e não deve ser - condicionante para a matrícula no AEE, mas muitas vezes a escola maquia esse cenário e exige uma condição de matrícula a partir desse documento (SANTIAGO; SANTOS; MELO, 2017). Para os autores, a questão do laudo suscita interpretações controversas. Nesse sentido, a fim de compreender se (e como) a existência do laudo auxilia ou não no processo de escolarização, perguntou-se aos entrevistados como eles concebem o uso do laudo médico na prática escolar. Os trechos abaixo ilustram algumas das visões sobre esse tema:

Na maioria dos casos, ele não interfere nem contribui para nosso trabalho e ações pedagógicas. (RESPOSTA QUESTIONÁRIO, 2019)

Não me faz diferença, pois foco no potencial da criança. (RESPOSTA QUESTIONÁRIO, 2019)

Na prática escolar eu não concebo. Não existe relação técnica e nem científica no fazer pedagógico. (RESPOSTA QUESTIONÁRIO, 2019)

Sem função prática. (RESPOSTA QUESTIONÁRIO, 2019)

Por outro lado, alguns dos profissionais da educação apresentaram pontos de vista diferentes sobre o assunto:

O laudo não pode ser ignorado, uma vez que existe. Porém, também não pode servir para limitar o trabalho, a capacidade do aluno, e tampouco determinar precocemente aonde este chegará, ou traçar um limite a seu desenvolvimento. (RESPOSTA QUESTIONÁRIO, 2019)

Penso que em muitos casos norteia o trabalho a ser desenvolvido, assegura seus direitos quanto a $\mathrm{ACl}$ e monitoria e quando necessário desenvolvimento de estratégias adequadas, respeitando seu tempo e funcionamento, buscando estímulos e possibilidades, mas não se deve ficar preso a esse laudo, pois há casos em que o laudo impossibilita o desenvolvimento da criança. Há médicos equivocados que dão laudos que, quando se conhece a criança, não se constata as indicações feitas em relação ao seu desenvolvimento. (RESPOSTA QUESTIONÁRIO, 2019)

Percebe-se novamente que os saberes da área da saúde adentram a escolarização, a fim de garantir direitos desconhecidos pelos médicos - saberes que dizem respeito apenas às questões do contexto e da demanda educacional. Pode-se pensar que um profissional da medicina dificilmente saberá do que se trata uma adaptação curricular individual $(\mathrm{ACl})$, conforme menciona um dos entrevistados. O fato é que as orientações médicas parecem exercer um poder sobre a área da educação, uma vez que elas se 
http://dx.doi.org/10.5902/1984686X41866

inserem no sistema educacional a convite dos educadores, com o objetivo, por vezes, de sustentar o não aprender como concebido socialmente.

A questão talvez não esteja na finalidade do laudo, mas naquilo que é feito com ele. Assim, passam a existir justificativas viáveis sobre o aprender diferente. Todavia, é preciso levantar questionamentos sobre as práticas do uso do laudo:

O laudo representa a constatação e oficialização por escrito de um profissional especialista que vai embasar todo o trabalho a ser desenvolvido com a criança. (RESPOSTA QUESTIONÁRIO, 2019)

Os diagnósticos, por si só, não contribuem para a boa intervenção junto ao aluno. Por vezes, o aluno, por seu diagnóstico, fica amarrado dentro do que é comum ao seu diagnóstico, limitando as possibilidades de cada indivíduo. Ter um diagnóstico não significa ser um diagnóstico. O diagnóstico deve servir para orientar os profissionais, mas não para restringir as possibilidades individuais. (RESPOSTA QUESTIONÁRIO, 2019)

Nesses dois fragmentos apresentados, percebe-se a dimensão das diferentes concepções da área da saúde que adentram a educação. Dessa forma, por um lado, o laudo detém, conforme a primeira resposta, a base do trabalho a ser desenvolvido com a criança. Mas que base educacional seria essa, fornecida por um laudo? $\mathrm{O}$ segundo fragmento ressalta o quanto o uso do laudo pode ser limitador da prática pedagógica, ou seja, enquanto um profissional percebe o laudo como base para o trabalho pedagógico, outro percebe como limitador da prática pedagógica. Nesse sentido, é válido questionar: a maneira como o educador percebe o laudo diagnóstico pode conduzir a abordagem pedagógica a ser desenvolvida no trabalho educacional?

Ao empregar o laudo como fundamental ou como instrumento orientador da prática pedagógica, deixa-se de considerar aspectos subjetivos dos sujeitos com deficiência. Focase naquilo que se diz, e não naquilo que se é, com suas múltiplas possibilidades. Para isso, a interdisciplinaridade se apresenta como alternativa de construção conjunta.

\section{Entre caminhos necessários: a construção conjunta}

O último questionamento apresentado aborda os aspectos relacionados às concepções que os educadores têm da necessidade ou não dos saberes da área da saúde para o desenvolvimento da prática pedagógica. Destaca-se que todos os tópicos abordados estão interligados e que questões anteriores a esta seção também respondem às questões presentes aqui. O Gráfico 4 mostra as respostas dos entrevistados a essa questão. 
http://dx.doi.org/10.5902/1984686X41866

Gráfico 4 - Os saberes da saúde para a educação

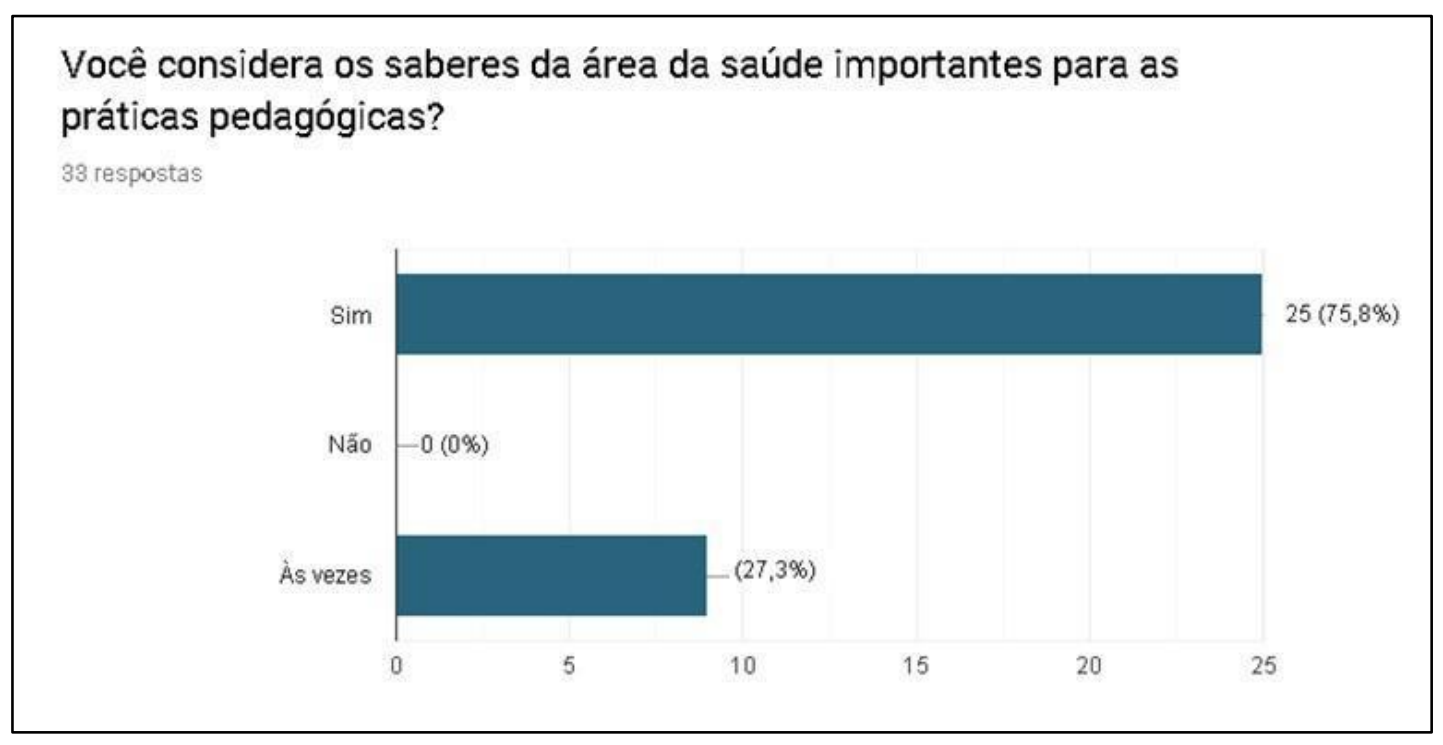

Fonte: Elaborado pelas autoras (2019).

Conforme o Gráfico 4, 25\% dos professores responderam que consideram importantes os saberes da saúde para as práticas pedagógicas. Um dos apontamentos que justificam a resposta traz a seguinte afirmação:

\begin{abstract}
A saúde contribui para a prática pedagógica no sentido de que temos que ter consciência das limitações que poderão contribuir para a não aquisição ou dificuldade de aquisição de conhecimento, até para que não haja grandes frustrações quando da não aquisição da aprendizagem. Acho que devemos unir os conhecimentos em busca do desenvolvimento e bem-estar do aluno. (RESPOSTA QUESTIONÁRIO, 2019)
\end{abstract}

Assim, pode-se pensar que a deficiência passa a ser o lugar. O lugar, por exemplo, é deficiente para o cadeirante por não dispor dos acessos necessários para ele. Outro aspecto que se evidencia nesse dizer é o significado que passar a ter o olhar da saúde do ponto de vista do docente, como determinante das limitações, em vez de um aliado para dar ênfase às potencialidades do aluno. Em outras palavras, foca-se na falta, e não nas possibilidades. Para Jerusalinsky e Lugon (2018), aquilo que está registrado no laudo acaba se tornando o único parâmetro que muitos profissionais têm da criança. Todavia, o caminho de um aluno com deficiência deve ser pensado a partir de um conjunto de atividades e recursos de acessibilidade e pedagógicos, e organizado pelo AEE. Reside aí não apenas a funcionalidade do AEE, mas a dinâmica que necessita da interdisciplinaridade para que o estudante não se torne o "estudante laudado". Nesse cenário, atitudes podem, às vezes, configurar-se como barreiras. 
http://dx.doi.org/10.5902/1984686X41866

Angelucci (2014) problematiza que diariamente educadores buscam cursos sobre aspectos das ciências da saúde, como se o conhecimento das patologias fosse necessário para que um projeto educacional possa existir. Porém, o eixo do educador é pedagógico, e não clínico. Para Palma e Carneiro (2018, p. 163), "a medicina trouxe grandes contribuições na descoberta de muitas síndromes", mas somente essa vertente não oportuniza a sociedade vê-la sob aspectos positivos. Há que se questionar a predominância da concepção médica em relação à deficiência na cultura escolar.

Outros educadores entrevistados manifestaram que talvez o laudo contribua para a relação pedagógica, no sentido de um trabalho articulado com outros profissionais que atendem o aluno vinculado ao AEE, apresentando as seguintes justificativas:

\begin{abstract}
Nem sempre o laudo representa aquilo que o aluno tem condições de apresentar, mas contribui no sentido de orientar algumas práticas pedagógicas. As duas áreas se complementam e são capazes de contribuir com o pleno desenvolvimento da criança quando se conversam e realizam um trabalho de parceria. (RESPOSTA QUESTIONÁRIO, 2019)
\end{abstract}

Quando o profissional é bom e comprometido, penso ser fundamental, pois quando o trabalho em rede acontece tudo funciona melhor, sendo essencial o diálogo, a troca de informações, para melhorar a vida deste sujeito. Ele deve ser visto como um todo e não em partes. (RESPOSTA QUESTIONÁRIO, 2019)

Penso que saúde e educação devem caminhar juntas. $O$ aluno com necessidades especiais, com deficiência, tanto física, intelectual ou emocional, tendo o atendimento médico adequado e sendo respeitado na sua individualidade no espaço escolar, tem condições de evoluir e crescer no processo de ensino aprendizagem. (RESPOSTA QUESTIONÁRIO, 2019)

Para Jerusalinsky e Lugon (2018, p. 1), diante da Nota Técnica nº 04, a interlocução clínico-escolar pode acontecer sem partir da "denominação doença". Assim, é preciso investir em propostas que incluam narrativas abertas e em permanente construção sobre - e até mesmo com - os sujeitos aprendentes, que se farão progressivamente mais presentes nas escolas. Conforme mostra o primeiro fragmento, apresenta-se o laudo como orientador de práticas pedagógicas. Porém, como poderia um laudo, contendo um código que se refere à taxonomia da suposta síndrome, transtorno ou deficiência, orientar a prática pedagógica? De que maneira o laudo médico de um profissional que não conhece o cotidiano educacional vai orientar a escolarização?

A Nota Técnica convoca os professores de AEE a articular-se com os profissionais da área da saúde. Sabe-se que os alunos PAEE muitas vezes demandam serviços de saúde, mas é importante haver uma equipe interdisciplinar, que possa auxiliar no processo de indicação e encaminhamento do aluno para o AEE (PASIAN; MENDES; CIA, 2013). Para 
http://dx.doi.org/10.5902/1984686X41866

isso, há a necessidade de perceber o aluno como sujeito, e não como assujeitado ao documento médico.

Consideramos relevante colocar em evidência os desafios na identificação e na superação de barreiras no processo de escolarização das pessoas com deficiência. Inclusão é, portanto, um processo infindável que precisa ser praticado coletivamente e de forma contextualizada.

\section{Considerações}

Discutir e compreender as concepções de profissionais da educação acerca do laudo e problematizar a exigência desse documento para 0 atendimento educacional especializado colabora para que outras áreas possam entender a importância da interdisciplinaridade e da valorização dos saberes educacionais. Nesse sentido, as concepções do laudo no processo de escolarização retratam a necessidade de disseminação das leis, dos decretos e, principalmente, da Nota Técnica № 04/2014, para que tais documentos possam guiar novas práticas educacionais no âmbito da educação inclusiva.

O laudo ainda é concebido, para muitos, como um importante instrumento na instituição educacional, com foco no ensino e na aprendizagem, embora as diferentes leis que preconizam sobre a educação especial mostrem uma história repleta de ações que buscam propor o direito à educação para além de taxonomias e diagnósticos. Entretanto, não parece estar clara, no espaço escolar, a finalidade do laudo médico, assim como as possibilidades trazidas pela Norma Técnica oㅡ 04, que não condiciona a matrícula no AEE à existência de um laudo médico. Se a apresentação do laudo ainda é condicionante para 0 atendimento em algumas instituições, isso significa que ainda existem escolas com barreiras ao acesso dos alunos de PAEE no AEE.

Nesse sentido, é preciso que sigamos os movimentos de constituição de práticas para que, quando os saberes da saúde adentrarem os muros da escola, não sejam para repetir a história já vista, mas para traçar um novo caminhar. Enquanto esses processos se constroem, é preciso pensar na finalidade educativa para cada sujeito. 
http://dx.doi.org/10.5902/1984686X41866

\section{Referências}

ANGELUCCI, Carla. Medicalização das diferenças funcionais: continuismos nas justificativas de uma Educação Especial subordinada aos Diagnósticos. Nuances: estudos sobre Educação, Presidente Prudente, v. 25, n. 1, p. 116-134, jan./abr. 2014.

BIANCHETTI, Lucídio. Aspectos históricos da educação especial. Revista Brasileira de Educação Especial, Piracicaba, v. 2, n. 3, p. 7-19, 1995.

BAPTISTA, Claudio Roberto; VIEGAS, Luciane Torezan. Reconfiguração da Educação Especial: Análise da Constituição de um Centro de Atendimento Educacional Especializado. Revista Brasileira de Educação Especial, Marília, v. 22, n. 3, p. 429442, set. 2016.

BONI, Valdete; QUARESMA, Sílvia Jurema. Aprendendo a entrevistar: como fazer entrevistas em Ciências Sociais. Revista Eletrônica dos Pós-Graduandos em Sociologia Política da UFSC, Florianópolis, v. 2, n. 1 (3), p. 68-80, jan.-jul./2005.

BRASIL. Ministério da Educação. Secretaria de Educação Continuada, Alfabetização, Diversidade e Inclusão. Nota Técnica no 04, de 23 de janeiro de 2014. Orientação quanto a documentos comprobatórios do cadastro de alunos com deficiência, transtornos globais do desenvolvimento e altas habilidades/superdotação no Censo Escolar. Brasília, DF, 2014. 4p.

BRASIL. Ministério da Educação. Secretaria de Educação Especial. Programa de implantação de salas de recursos multifuncionais. Brasília, DF, 2010. 33p.

BRASIL. Casa Civil. Decreto n 7.611, de 17 de novembro de 2011. Brasília, DF, 2011. $4 p$.

BRASIL. Conselho Nacional de Educação. Resolução CNE/CEB no 4, de 2 de outubro de 2009. Diretrizes Operacionais para o Atendimento Especializado na Educação Básica, modalidade Educação Especial. Brasília, DF, 2009. 3p.

BRASIL. Ministério da Educação. Secretaria de Educação Especial. Política Nacional de Educação Especial na Perspectiva da Educação Inclusiva. Brasília: MEC/SEESP, 2008. 19p.

CANGUILHEM, Georgs. O normal e o Patológico. 5. ed. Rio de Janeiro: Forense Universitária, 2002.

COLOMBANI, Fabiola; MARTINS, Raul Aragão. O movimento higienista como política pública: aspectos históricos e atuais da medicalização escolar no Brasil. Revista on-line de Política e Gestão Educacional, Araraquara, v. 21, n. 1, p. 278-295, abr. 2017.

DALFOVO, Michael Samir; LANA, Rogério Adilson; SILVEIRA, Amélia. Métodos quantitativos e qualitativos: um resgate teórico. Revista Interdisciplinar Científica Aplicada, Blumenau, v. 2, n. 4, p. 01-13, sem II. 2008. 
http://dx.doi.org/10.5902/1984686X41866

FOUCAULT, Michel. Vigiar e Punir: nascimento da prisão. Trad. Lígia M. Ponde Vassalo. Petrópolis: Vozes, 1987.

FOUCAULT, Michel. Em defesa da sociedade: curso no Collège de France (1975 1976). Trad. Maria Ermentina Galvão. São Paulo: Martins Fontes, 1999.

FRANÇA, Tiago Henrique. A normalidade: uma breve introdução à história social da deficiência. Rev. Brasileira de História \& Ciências Sociais, v. 6, n. 11, p. 105-123, jul. 2014.

GALLI-FONSECA, Tania Mara. Arquivo e testemunho da Psicologia como Ciência e Profissão. Psicologia: Ciência \& Profissão, Brasília, v. 32, n. 1 (especial), p. 18-27, 2012.

JERUSALINSKY, Julieta; LUGON, Ricardo. Inclusão sem laudo é um direito da criança! Jornal Estadão, São Paulo, 2016. Disponível em:

https://emais.estadao.com.br/blogs/crianca-em-desenvolvimento/inclusao-sem-laudo-eum-direito-da-crianca/. Acesso em: 29 out. 2019.

KRANZ, Cláudia Rosana; CAMPOS, Herculano Ricardo. Educação Especial, Psicologia e Políticas Públicas: O diagnóstico e as práticas pedagógicas. Psicol. Esc. Educ., Maringá, v. 24, 2020.

LIMA, Solange Rodovalho; MENDES, Enicéia Gonçalves. Escolarização da pessoa com deficiência intelectual: terminalidade específica e expectativas familiares. Revista

Brasileira de Educação Especial, Marília, v. 17, n. 2, p. 195-208, Aug. 2011.

\section{MATHIAS, Sergio Larruscaim; SAKAI, Celio. Utilização da Ferramenta Google Forms} no Processo de Avaliação Institucional: estudo de Caso nas Faculdades Magsul, 2013. Disponível em:

http://download.inep.gov.br/educacao_superior/avaliacao_institucional/seminarios_regiona is/trabalhos_regiao/2013/centro_oeste/eixo_1/google_forms_processo_avaliacao_instit_e studo_caso_faculdades_mag.pdf. Acesso em: 16 jun. 2019.

MINAYO, Maria Cecília de Souza. (Org.). Pesquisa social: teoria método e criatividade. 17ํㅡㄹ ed. Petrópolis: Vozes, 1994.

PALMA, Debora Teresa; CARNEIRO, Relma Urel Carbone. O Olhar Social da Deficiência Intelectual em Escolas do Campo a Partir dos Conceitos de Identidade e de Diferença. Revista Brasileira de Educação Especial, Bauru, v. 24, n. 2, p. 161-172, abr. 2018.

PASIAN, Mara Silvia; MENDES, Enicéia Gonçalves; CIA, Fabiana. Aspectos da Organização e Funcionamento do Atendimento Educacional Especializado: Um Estudo em Larga Escala. Educação em Revista, Belo Horizonte, v. 33, p. 1-18, abr. 2017.

RAMOS, Carolina Lehnemann. O "laudo" na inclusão de alunos no ensino regular: uma estratégia da governamentalidade biopolítica. In: ANPED SUL, 10., Florianópolis. Anais... Florianópolis: UDESC, 2014. p. 1-15. Disponível em: http://xanpedsul.faed.udesc.br/arq_pdf/1947-0.pdf. Acesso em 10 jan. 2020. 
http://dx.doi.org/10.5902/1984686X41866

RICHARDSON, Roberto Jarry. Pesquisa social: métodos e técnicas. São Paulo: Atlas, 1989.

ROSÁRIA-BARBOSA, Deborah; SOUZA, Marilena Proença Rebello. Psicologia Educacional ou escolar? Eis a questão. Rev. Bras. de Psicologia Escolar e Educacional, Maringá, v. 16, n. 1, p. 163-173, jan./jun. 2012.

SANTIAGO, Mylene Cristina; SANTOS, Mônica Pereira dos; MELO, Sandra Cordeiro de. Inclusão em educação: processos de avaliação em questão. Ensaio: Avaliação e Políticas Públicas em Educação, Rio de Janeiro, v. 25, n. 96, p. 632-651, set. 2017.

SANTIAGO, Mylene Cristina; SANTOS, Mônica Pereira dos. Planejamento de Estratégias para o Processo de Inclusão: desafios em questão. Educação e Realidade, Porto Alegre, v. 40, n. 2, p. 485-502, jun. 2015.

SATHLER, Conrado. Escrita disciplinar e Psicologia: laudos como estratégia de controle das populações. 2008. 233 f. Tese (Doutorado em Linguística Aplicada) Programa de Pós Graduação em Linguística Aplicada, Universidade Estadual de Campinas. Campinas: Unicamp, 2008. Disponível em:

http://repositorio.unicamp.br/bitstream/REPOSIP/269481/1/Sathler_ConradoNeves_D.pdf. Acesso em 29 out. 2019.

VIEIRA, Alexandro Braga; RAMOS, Ines de Oliveira. Diálogos entre Boaventura de Sousa Santos, Educação Especial e Currículo. Educação e Realidade, Porto Alegre, v. 43, n. 1, p. 131-151, mar. 2018.

\section{Notas}

${ }^{1}$ Conforme a Lei de Diretrizes e Bases da Educação Nacional, Lei nº 9394 de 1996, "Inciso II - terminalidade específica para aqueles que não puderem atingir o nível exigido para a conclusão do ensino fundamental, em virtude de suas deficiências, e aceleração para concluir em menor tempo o programa escolar para os superdotados".

2 Denominação da região próxima da capital do Rio Grande do Sul, Porto Alegre, composta de 14 municípios banhados pelo Rio dos Sinos.

3 Todos os excertos relativos às respostas dos participantes respeitarão esta formatação. 